\title{
TRANSUASÃO E COGNOSCIBILIDADE NA POESIA DE DURVALINO COUTO TRANSUASION AND COGNOSCIBILITY IN DURVALINO COUTO'S POETRY
}

\author{
Feliciano José BEZERRA Filho \\ Universidade Estadual do Piauí (UESPI) \\ felicianofilho@uol.com.br \\ Josivan Antonio do NASCIMENTO \\ Universidade Estadual do Piauí (UESPI) \\ josivnascimento@outlook.com
}

RESUMO: Este artigo, adaptado de capítulo de dissertação, examina como a poesia de Durvalino Couto expressa cognoscibilidade a partir da semiose dos signos verbais no poema. A análise considera o signo in continuum numa relação triádica a fim de elucidar a transuasão que acarreta o universo cognoscível que representa. 0 estudo leva em conta as contribuições teóricas de Peirce (2010, CP. 1931-1958, 8 vols.), Chandler (2007), Pignatari (2004) e outros. As discussões propostas revelam que a poesia é um arcabouço que se torna cognoscível através da transuasão de conceitos como signos verbais em obsistência com o não-verbal. Essa transuasão constrói um conceito geral para uma representação metafórica daquilo que o poema não é. Por conseguinte, o poema se torna um universo verbal capaz de performar cognição para um possível interpretante.

Palavras-chave: Poesia. Signo. Cognoscibilidade. Transuasão.

ABSTRACT: This paper, adapted from a dissertation chapter, examines how Durvalino Couto's poetry can express cognoscibility through the semiosis of verbs signs in a poem. The analysis considers the sign in continuum in a triadic relation in order to elucidate the transuasion that entails the cognizable universe it represents. The study highlights the theoretical framework provided by Peirce (2010, CP, 1931-1958, 8 vols.), Chandler (2007), Pignatari (2004) and others. The intended discussions revealed that poetry is a framework that becomes cognizable through the transuasion of concepts acting as verb signs in obsistence with the non-verbal. This transuasion creates a general concept standing for a metaphorical representation of what the poem is not. As a result, the poem becomes a verbal universe able to perform cognition for a possible interpretant.

Keywords: Poetry. Sign. Cognoscibility. Transuasion.

Epígrafe:

Whatever is real is the law of something less real. ${ }^{1}$ Charles Sanders Peirce

Introdução.

Este artigo é um recorte de capítulo da dissertação de Mestrado intitulada Os caçadores de prosódias (1994): uma análise semiótica da poesia de Durvalino Couto defendida pelo programa de pós-graduação em letras da Universidade

1 "Qualquer coisa que seja real é a lei de algo menos real." 
Estadual do Piauí (UESPI) em 2018. 0 contexto-fonte dessa pesquisa considera o poema como um arcabouço sintático capaz de produzir cognoscibilidade. Considerando que a poesia manifesta-se como uma potência lexical a conjugar na mente o efeito do verbo. Também, discute como o signo verbal se torna capaz de estabelecer uma relação cognoscível entre os elementos que constituem seu universo verbal. A análise leva em conta as contribuições teóricas de Peirce (2010, CP. 1931-1958, 8 vols.), Chandler (2007), Pignatari (2004) e outros.

\section{Discussão teórica.}

Através da iconicidade e obsistência entre os signos o poema se torna visível. A cognitividade do poema se dá através da relação por transuasão entre esses signos, que acarretam uma relação triádica formando assim a Terceiridade. Peirce (2010) descreve que essa categoria de signo caracteriza-se pela participação de um terceiro signo: o interpretante. Sendo um signo que mantém a relação entre o representâmen (signo monádico) e o objeto (signo diádico), o interpretante é responsável por formar uma semiose através da inter-relação entre essas categorias (PEIRCE, 2010). Chandler (2007) pontua que o signo é um representâmen que é uma unidade pela qual um objeto é representado. A forma como esse representâmen é interpretado acontece através do interpretante que torna a relação signo-objeto cognoscível. Dessa forma, a Terceiridade constitui um ser que é tal como é em função de relacionar um segundo com um terceiro (ARAÚJO, 2004; PEIRCE, CP. 8.328; PIGNATARI, 2004, p. 43; SANTAELLA, 1992, 2007). Neste sentido, toda Terceiridade engloba Primeiridade e Secundidade, mas nunca o inverso (DEELY, 1990; DE WAAL, 2007). Essas três categorias de signos formam o que Peirce chama de categorias cenopitagóricas, às vezes mencionadas pelo próprio autor como Ceno-Pythagorean Categories (PEIRCE, CP. 2.87), cenopythagorean categories (PEIRCE, CP. 1.351-352; 2.116; 8.328-329) e Kainopythagorean categories (PEIRCE, CP. 7.528; 7.531; 7.536-537).

Um signo terceiro é um signo de lei que media um primeiro e um segundo por meio do pensamento, raciocínio, mediação, condução, transuasão, lógica, convenção social ou meios correlatos que tornam a mente em signo interpretante. Dessa maneira, as palavras funcionam como legissignos ou signos que só assumem 
um sentido em virtude da relação com outras palavras (MERRELL, 2005; PIGNATARI, 2004). Ainda assim, a relação entre elas se dá por meio do encadeamento lógico que condiciona a estrutura e funcionalidade da língua.

Os signos que formam a Terceiridade evidenciam o poder cognitivo que eles evocam, pois são resultantes de uma lei que determina o sentido do próprio signo. Pode-se considerar como exemplo o processo que condiciona a distinção de um texto que é poema de outros que não o sejam. 0 conceito parte de uma generalização que é concebida a partir de um interpretante que media a relação entre o signo e o objeto. 0 ser poema em sua estética constitui um encadeamento lógico entre os signos mantendo um diálogo entre si e o universo cognoscível que representam. Badiou (2002, p. 46) pondera que "a verdadeira relação do poema se estabelece entre o pensamento, que não é um sujeito, e a presença, que ultrapassa o objeto". Isso demonstra que o poema, em seu nível sintático, apresenta-se como um efeito lógico que determina a obsistência provocada entre os signos que sustentam sua clausura. A presença revela-se entre a clausura e a rasura do arcabouço poético, isto é, a partir do encadeamento lógico-discursivo que se desenvolve por uma obsistência entre poema e não-poema, linguagem e nãolinguagem. A originalidade qualitativa da poesia impregna na composição sintática um valor semântico que transborda o próprio verbo, fazendo deste um universo sígnico onde a cognição objetiva a conjugação da linguagem através de um universo maior. Esse universo é composto de categorias de signos que se relacionam entre si por meio do interpretante que determina sua atuação como signo.

Chandler (2007) critica que a classificação dos signos apresentada por Peirce não pode ser concebida sem levar em conta o propósito para o qual tal signo possa ser usado num contexto específico. Chandler considera que um simples mapa, por exemplo, pode ser considerado ícone, índice ou símbolo, o que depende de sua função como signo. Diante disso, nota-se que Chandler destaca um aspecto que ultrapassa a essência do próprio signo: a sua funcionalidade. Todavia, mesmo que um signo possa assumir ao longo do tempo diferentes vieses entre pessoas de épocas diversas, não se pode negar que a essência que caracteriza um ícone não é a mesma do índice e nem do símbolo. Considerar um ícone como um símbolo apenas 
reforça a arbitrariedade que o signo possui diante da possibilidade do objeto que representa. Neste sentido, quando Peirce (2010) diz que um signo só funciona como tal quando alguém o considera signo, então a essência que um signo possui surge de sua funcionalidade, o que não se confunde com a essência que distingue um ícone de índice ou símbolo. Isso implica que, dessa maneira, embora um mesmo signo possa assumir a essência de classes de signos diferentes, não se pode negar que existem modelos de relação signo-objeto que asseguram determinar um signo conforme seu modo de relação com o objeto, independentemente de sua funcionalidade.

Levando em conta essa dimensão do signo em essência e funcionalidade, destaca-se que a sintaxe do poema constitui-se da mesma maneira, já que é formado por signos. De certo modo, se a essência do signo consiste em sua funcionalidade, então, pode-se afirmar que toda referência atribuída ao signo é, antes de tudo, simbólica. Pois todo signo representa aquilo que ele não é. Logo, a representação implica simbolizar o que não é cognoscível sem a representação. Se um poema funciona como ícone para uma determinada introspecção psicológica de um sujeito lírico e, a partir de outro viés, o mesmo texto passa a ser um símbolo que marca a característica de uma geração literária ou ainda representa o uso refinado de uma língua específica na sua forma poética, certamente o poema se torna um signo cuja essência sui generis nunca pode ser de facto acessível em seu caráter per si. Dessa forma, isso seria o mesmo que buscar compreender o mundo e as coisas sem uma linguagem que pudesse traduzir em pensamento e raciocínio os objetos pertencentes a este universo. Assim, se, por um lado, a crítica de Chandler justifica a arbitrariedade do signo, por outro, ela dissipa do signo a essência genuína hic et nunc devido a ênfase dada à funcionalidade do signo. Daí surge a necessidade de entender o signo numa estância filosófica que abarque o próprio signo em si mesmo, a representação e a realidade, tal como cunha Chandler (2007).

A defesa da essência do signo sui generis como uma experiência hic et nunc é concebida por Peirce como uma categoria de signo chamada de actisign (atissigo). São signos que expressam a essência singular de um signo como um evento único encerrado em si mesmo em um determinado instante, tal como a palavra de um texto numa página de uma determinada cópia de um livro (PEIRCE, CP, 8.347). 0 
efeito da singularidade de um signo dentro de um instante no tempo e no espaço remonta à ideia de Paz (2009) ao afirmar que o poema constitui-se de signos que são insubstituíveis. Cada palavra possui dentro do poema uma singularidade que não pode ser substituída por outra. 0 efeito da poesia reside nessa singularidade do signo, tornando o poema um conceito. Desse modo, embora o poema seja constituído de signos regidos em sua própria singularidade, a generalização do poema é a negação da heterogeneidade que constrói o conceito homogêneo. Nomear um texto de poema é, ao mesmo tempo, negar a essência das unidades mínimas que compõem o arcabouço sintático do próprio texto. A generalização não é dicotômica e que não se encerra na relação causa e efeito. A generalização é transuasiva. Logo, é triádica. Nesse sentido, todo poema se torna uma metáfora do objeto ao qual se refere. Primeiro porque representa o objeto parcialmente: a qualidade do objeto se limita ao propósito e ao ângulo pelo qual foi observado e traduzido em linguagem pelo sujeito lírico. E, segundo, pelo fato de a representação do objeto dar-se através de palavras, que são símbolos que expressam a ideia das coisas, sem serem elas propriamente ditas (PEIRCE, CP, 2.298).

Embora não tenham como objeto aquilo que não são, as palavras podem representar a si mesmas, como na metalinguagem. 0 poder de uma palavra sugerir uma ideia quer seja ela mesma ou não, deve-se à comunidade do interpretante que condiciona tal essência na linguagem. Essa referência ao interpretante como parte da comunidade é discutida por Kress (2005) ao considerar que o signo se torna um efeito do social. A combinação do significante com o significado (signo/objeto) resulta de contingências histórico-sociais num determinado meio, incluindo relações de poder e solidariedade. Isso possibilita a linguagem representar certo objeto, tanto tal como ele poderia ser, como também distorcer a ideia da essência desse objeto. Surge daí a necessidade de elucidar a semiose que torna o poema cognoscível.

Ao desenvolver-se a partir de um sistema de signos que são regidos por um interpretante, a poesia abrange um universo sintático heterogêneo cuja fronteira é reconstruída a cada leitura condicionada pelo espaço-tempo. Peirce determina que o interpretante pode ser imediato, dinâmico e final. 0 primeiro pode ser entendido 
como a qualidade que certa assertiva contém em sua clausura. 0 dinâmico se refere ao impacto provocado pelo propósito que condiciona o interpretante imediato. E o final é o argumento que resulta do diálogo entre o interpretante imediato e o dinâmico. Todavia, na poesia o que se pode defender é a existência de um interpretante final apenas para cada leitura ou modo de reconhecer o signo que compreende uma parcela do universo que o poema representa. Se a poesia se restringisse a um interpretante final e absoluto, o poder metafórico do poema se reduziria a apenas um conceito lógico. Logo, não seria poesia. Para Badiou (2002), o poema situa-se numa operação que se faz presença sobreposta à sua objetividade:

Essa ideia é capital: o poema não é nem uma descrição, nem uma expressão. Tampouco é uma pintura comovida da extensão do mundo. 0 poema é uma operação. 0 poema nos ensina que o mundo não se apresenta como uma coleção de objetos. 0 mundo não é aquilo que coloca objeção ao pensamento. É - para as operações do poema aquilo cuja presença é mais essencial que a objetividade. (BADIOU, 2001, p.44).

A partir de Badiou é possível considerar que o poema é uma presença cujo efeito se desloca de sua iconicidade e o poder de representação. A operação do poema estabelece a presença como a própria cognitividade poética. No entanto, até que ponto essa presença sobrepõe a objetividade que condiciona tal presença? Embora a experiência da presença construa uma cognição que transborda os limites da linguagem, seria equivocado conceber o poema como uma presença absoluta quando seu arcabouço resulta da tradução de outras operações, ocorrendo no nível introspectivo. Pensar o poema é repensar a cognição que o condiciona. A experiencia no poema parte de um pensamento traduzido de outro. Peirce (CP. 7.337) postula que a experiência direta parte do próprio pensamento que causa outro, construindo uma rede de raciocínio cujo início e fim não são claramente delimitados.

Isso implica que o poema constitui-se de signos que funcionam como fatores externos a fim de provocar, associar e desenvolver o pensamento por ele representado. 0 pensamento não está no signo e tampouco no objeto. Está no interpretante que determina o signo pelo qual o pensamento é traduzido através do poema. Desse modo, a presença do poema tal qual se pode considerar a partir 
de Badiou engloba tanto o pensamento que o eu lírico traduz em linguagem quanto o encadeamento lógico que possibilita o signo funcionar como tal e provocar o efeito poético. 0 diálogo entre esses dois universos possibilita o poema produzir um efeito metafórico plural. A diversidade com que as coisas podem ser concebidas parte das relações diversas que o sujeito pode ter em relação a elas, como defende Peirce (CP. 7.335).

A elucidação da cognoscibilidade como fenômeno pertencente à presença do poema tem como propósito o efeito poético. Não sendo a coisa em si, o objeto poético a ser construído decompõe-se, a partir da generalização da linguagem, como signo ao constituir-se como tal no interpretante. 0 arcabouço sintático é composto de signos que em semiose afloram seu poder metafórico. É o processo que torna o signo cognoscível, como se pode perceber no poema seguinte:

\title{
NÃO SEREI CLEMENTE
}

\author{
Não existe literatura \\ No Piauí \\ em Sampa \\ ou Singapura \\ quando \\ apenas \\ retoco \\ minha obra \\ única \\ com um toco \\ de pena, , , , , \\ como quem bota florzinhas \\ no próprio túmulo \\ (DURVALINO COUTO, 1994, p.107)
}

Durvalino Couto apresenta um poema no qual a inclemência do sujeito lírico se torna próprio objeto de representação poética. 0 poema exige do eu poético mais do que uma codificação sintática. A literatura tal como critica o sujeito deve transbordar as fronteiras da linguagem no verso. Assim, até que ponto esse arcabouço deve se sobrepor à objetividade que condiciona sua presença? Certamente o sintático poético não se sobrepõe à cognição que produz em função de o poema resultar do próprio interpretante. Esse signo terceiro é o fator que 
decompõe o efeito poético de um determinado texto e o classifica como poema. As palavras do poema são legissignos, que é um signo de lei e que comporta sinsignos (PEIRCE, 2010; PIGNATARI, 2004; SEBEOK, 2001). A classe gramatical de cada palavra do poema é um dos principais fatores que determina a essência do signo envolvido e sua participação na construção de sentido no poema. No poema citado anteriormente, o substantivo atua como um signo terceiro que direciona o interpretante ao objeto poético, cuja essência corresponde ao Símbolo Remático ou Rema Simbólico descrito por Peirce em sua 8o classe de signo:

Um Símbolo Remático ou Rema Simbólico (e.g. um substantivo comum) é
um signo ligado a seu Objeto através de uma associação de ideias gerais
de tal modo que sua Réplica traz à mente uma imagem a qual, devido a
certos hábitos ou disposições dessa mente, tende a produzir um conceito
geral, e a Réplica é interpretada como um Signo de um Objeto que é um
caso desse conceito (PEIRCE, 2010, p. 56).

Diante disso, o poema assume uma essência que se manifesta a partir de sua operação sintática endofórica, que está para um universo transuasivo no nível do interpretante. Ambos os processos constituem em diálogo o efeito poético da linguagem. Em seu arcabouço, existem signos que se relacionam por meio de diferentes categorias. A inter-relação entre essas categorias se desenvolve numa semiose que, por seu turno, produz um objeto poético plural, tendo como base um arcabouço icônico singular. No nível da Terceiridade, as palavras que participam de relações triádicas devem ser observadas, tanto no nível sintático (arcabouço icônico), como no cognitivo (efeito obsistente-transuasivo). Ambos os processos são imprescindíveis um do outro. 0 primeiro corresponde à presença com a qual o poema se manifesta (linguagem, métrica, sonoridade...); o segundo corresponde ao efeito cognitivo que tal presença provoca num determinado interpretante. Cumpre lembrar ainda que, antes que o poema se torne presença, é preciso que um interpretante determine a composição do poema, cujo efeito de composição pode ou não ser o mesmo do efeito de produção de sentido.

No âmbito sintático-cognitivo, pode-se considerar o substantivo e o verbo como as duas principais classes gramaticais cuja relação signo-objeto se dá através de um processo transuasivo que ordena a intersemiose entre o que é e o que não é linguagem. Esse modo de relação triádica difere das outras classes de palavras ao possuir um objeto que não é a própria linguagem, como as conjunções, os 
advérbios e as preposições, por exemplo. Esses tipos de signos atuam como legissignos que se diferenciam por sua respectiva réplica dentro de um contexto, como é o caso dos atissignos. Por outro lado, um substantivo possui um objeto que é um conceito geral. Ele representa apenas a ideia que se implica de um objeto que não é a coisa de fato em sua singularidade. Assim, os substantivos representam, por convenção social, a presença do abstrato e do concreto como uma experiência imediata do interpretante em um determinado instante. Por conseguinte, o verbo representa as ações e o estado pelo qual certa experiência acontece no tempo e no espaço. Em resumo, verbos e substantivos (sintático-cognitivamente) funcionam como símbolos. A singularidade de seu objeto é constituída do universo do interpretante do receptor. Isso torna o poema numa operação metafórica: a constituição do efeito cognitivo daquilo que representa o que não é.

Os substantivos comuns literatura, obra, toco, pena, florzinhas e túmulo ao lado dos substantivos próprios Piauí, Sampa e Singapura servem como signos que possam representar a ideia de que o eu pretende traduzir em linguagem. Os substantivos refletem o sentido dos verbos existir, retocar e botar. No entanto, como assegurar que o objeto poético de fato possa ser o mesmo que o sujeito compreende no nível introspectivo se os signos que compõem o poema são apenas conceitos gerais? Certamente o efeito surge pelo fato de os signos representarem a ideia da coisa, e não a coisa em si. Os signos que designam os conceitos apresentados pelos substantivos e as demais classes de palavras constituem um poema cujas fronteiras metafóricas transbordam a própria sintaxe. Esse efeito não seria possível se os conceitos fossem substituídos pelas coisas que representam. Isso quer dizer que uma cidade, um estado, uma obra, um toco de pena, e várias flores não são e tampouco fazem um poema. Todavia, a ordenação dos conceitos que designam essas coisas em si de fato constitui um poder comunicativo que pode assumir a essência de poesia. Uma cesta com flores não é um poema, mas a orquestração dos conceitos que a representa se torna poesia. 0 que produz o efeito não é a coisa em si, mas a ideia que se tem delas quando são acessíveis ao interpretante por meio de um sistema de signos. Desse modo, a cognoscibilidade do poema surge, então, da operação sintático-cognitiva de sua estrutura e a 
funcionalidade de seus signos como símbolos que, segundo Peirce, podem ser compreendidos a partir de três categorias:

Os símbolos, e de alguma maneira outros Signos, podem ser Termos, Proposições ou Argumentos. Um Termo é um signo que deixa seu Objeto e, a fortiori seu Interpretante, ser aquilo que ele pode ser. Uma Proposição é um signo que indica distintamente o Objeto que denota, denominado de seu Sujeito, mas que deixa seu Interpretante ser aquilo que pode ser. Um Argumento é um signo que representa distintamente o interpretante, denominado de sua Conclusão, que ele deve determinar (PEIRCE, 2010, p. 29, grifo do autor).

Se um símbolo pode ser compreendido como Termo, Proposição e Argumento e um poema se ordena em torno de símbolos, então a cognição do poema pode ser compreendida a partir das seguintes premissas:

a) Primeiro: se a literatura transborda o toco de pena, retocando uma obra única, minha obra não é um túmulo.

b) Segundo: retoco minha obra única.

c) Terceiro: não faço literatura.

A defesa da obra como túmulo desenvolve uma metáfora para criticar o fazer literário como uma atividade centrada na própria finitude do sujeito lírico. Isso implica que o fazer literário deve transcender a obra, o sujeito e o universo que ela representa. A transcendência parte tanto do signo que se traduz em conceito geral para representar uma ideia que nunca pode ser exata ou absoluta.

O que mais chama a atenção é o poder que o signo tem para expressar o sentido proposto e, ao mesmo tempo, possibilitar um universo de leitura, além da própria linguagem sem fugir dela. Certamente esse poder simbólico e metafórico se dá, não só no nível da organização sintática e estética, mas também através do interpretante que media o signo e o sentido. É esta cognição resultante desse processo que constrói uma transuasão.

O processo de transuasão no poema acontece quando o signo possui a capacidade de expressar cognição para um determinado interpretante, pertencente ao mesmo universo de representação do signo. Peirce (2010, p. 27) destaca que a transuasão sugere translação transação, transfusão, transcendental por ser "[...] mediação, ou a modificação da primeiridade e da secundidade pela terceiridade, tomada à parte da secundidade e da primeiridade; ou, é ser enquanto cria Obsistência". No nível do interpretante, a transuasão nesse caso opera quando 
condiciona a um signo a capacidade de veicular certa informação a respeito de um objeto sob determinada circunstância ou funcionalidade, cujo processo acarreta outro objeto por formar outro signo a partir do primeiro. Seja tomada como exemplo a seguinte pergunta: quando é que existe literatura? Considerando esse questionamento como signo primeiro, releva-se que a elaboração parte do universo de conhecimento de mundo do próprio enunciador. Levar em conta que a literatura passa a existir a partir de um determinado espaço de tempo implica que o processo de construção e composição da arguição parte da ausência dessa informação. Não saber quando de fato a literatura passa a existir implica, de certo modo, que o sujeito conhece que ela existe a partir de certo momento. A busca pelo quando se desenvolve e traduz-se em linguagem, tornando-se signo que, por seu turno, produz um efeito de cognição no interlocutor. A obsistência produzida pela pergunta, que é signo, causa uma reação no interlocutor que passa a refletir sobre o possível objeto, levando em conta o universo de conhecimento que possui. A reflexão sobre a pergunta também se caracteriza como uma busca por um quando entre todos os quando possíveis. Desse processo, algumas informações são traduzidas em linguagem que se torna signo para se manifestar como uma possível resposta.

Em busca pelo quando no poema "Tresidelas", pode-se afirmar que a afirmação de quando a literatura existe parte da negação de sua existência, ou seja, daquilo que ela não é. 0 argumento pode ser acarretado através do termo $a$ literatura não existe apenas sob alguma situação e a proposição existe apenas alguma situação que nega a literatura. A literatura como existir é primeiramente concebida a partir do que a impede como existência. A comparação entre o ato de retocar a obra e o de botar flor no túmulo revela duas situações que acarretam um terceiro: o existir literário como metáfora. 0 retoque da obra única manifesta-se como o efêmero do fazer literário. 0 enfeite encobre o poder de transcendência da obra além de sua clausura. Assim, para haver literatura é preciso que uma obra não se torne túmulo de si mesma. As flores simbolizam o retoque de uma obra que se dissipa em sua própria efemeridade por tornar breve a essência literária. Ainda assim, assume-se que esse poder de cognição só se atinge a partir da própria clausura do poema, embora seja um retoque do sujeito lírico. 
Considerando a produção de cognição através desse processo, pode-se dizer que a transuasão no poema apenas espelha um interpretante primário que traduziu certas introspecções em linguagem verbal. A elucidação desse processo pode ser claramente percebida através da seguinte experiência verbal:

ãNo xieset rauleitart
on iPuaí
me Spama
uo Supingara
noudaq
esanpa
croteo
hamin baro
cúnia
moc mu coto
ed pane,,',',',
',',',',',',',',','
moco mueq tabo sfalorzhin
on rópripo lútumo

Essa experiência verbal revela que transuasão-cognição do poema é o processo que produz cognição. A inversão de letras rompe com o sentido do verbo. Embora uma produção textual desse tipo possa ser feita, propositalmente, como uma experiência estética, o código per si não veicula um interpretante capaz de expressar, acuradamente, a ideia ou o propósito da composição, pois necessita de um objeto além do verbo. Isso revela que, mesmo mantendo as palavras na mesma posição em cada verso, a alteração lexical produz um tipo de palavra que não acarreta nenhum objeto e que, por conseguinte, não possui um interpretante. Mesmo que essa forma de conjugação sintática tivesse algum objeto, ele se limitaria ao interpretante que poderia manter essa forma de escrita como um código secreto para a troca de informações. Neste sentido, o avesso do poema pode ser entendido como a tênue relação que se estabelece entre o signo e o objeto. Às vezes, a linguagem é tratada de modo como se ela fosse de fato aquilo que se pretende representar. Construir um sentido para o poema em seu avesso é dizer tudo o que ele pode ou poderia ser, mas não o que ele é em função de não apresentar um sistema de signo acessível a um determinado interpretante. Dessa forma, a poesia se torna algo mais do que um simples processo de representação de um objeto em linguagem. A partir de Chandler (2007), considera-se que, além 
da reprodução da coisa em si, a representação constitui-se também num modo de construção da realidade.

As considerações de Chandler sobre a representação como construção de uma realidade reforça a ideia de repensar a poesia além de seu efeito cognitivo por uma obsistência transuasiva vinculada à sua clausura icônica. 0 arcabouço sintático do poema, embora às vezes não assuma contorno visual conforme o objeto retratado, possui uma iconicidade por se manifestar como uma presença que é uma imagem. Desse modo, a imagem se ordena em torno de uma composição sintática que acarreta o interpretante que o condiciona como poder de cognição. Sem essa coordenação lógica compreende-se que o poema perde o efeito de sentido, como se observa na citação do poema com mudança na posição das letras de cada palavra. Diante disso, pode-se inferir que a organização textual reflete o próprio encadeamento de ideias que se dá no nível do interpretante ao se manifestar como forma de produção de ideias, valores, atitudes, crenças, conhecimento e práticas através de códigos e subcódigos (CHANDLER, 2007). Esses códigos, por fim, transcendem a si mesmo ao implicar outros textos e códigos diversos, formando um universo de intersemiose in continuum ad infinitum.

Essa forma de percepção do poema constata que, mesmo não residindo em si o sentido que expressa, o poema escrito é uma imagem que se faz parte do mundo objetivo. A transuasão permite que a relação entre os signos que constituem o poema seja capaz de expressar um poder cognitivo que ultrapassa as fronteira do texto. Se isso não fosse possível, todo poema - como também um texto em prosa - poderia ser considerado como um espelho ao avesso, isto é, sem reflexo. Sem a transuasão, o poema seria apenas um signo possível sem acarretar um conceito geral. Logo, não haveria sentido.

Considerando que o efeito cognitivo de um poema constitui-se na transuasão, então é possível considerar que esse processo de construção de sentido deve acontecer de dois modos distintos: endofórica e exoforicamente. 0 primeiro diz respeito à transuasão que se estabelece no interior de um mesmo poema através da relação entre os signos que o constituem, podendo ser chamada de transuasão sintático-endofórica. 0 segundo, por seu turno, acontece quando o poema assume a essência de veicular informação cujo objeto não seja o próprio 
signo, criando um conceito geral através de um interpretante. Esse processo de cognição pode ser chamado de transuasão sintático-endoexofórica, pois considera tanto a relação entre o signo verbo-visual como o universo de ideia que se implica da semiose. ${ }^{2}$

\section{Conclusão}

A partir dos pontos discutidos neste recorte de pesquisa, é possível apontar que no âmbito da terceiridade o poema constitui seu poder de cognitividade a partir da relação transuasiva que se estabelece entre as palavras que sustentam seu arcabouço. Clausura e rasura revelam a cognoscibilidade poética entre verbo e não-verbo, presença e vazio. Considerando sua funcionalidade, o poema atua como signo que é uma representação metafórica daquilo que ele não é. A singularidade de seus atissignos constrói um efeito cognoscível em virtude de atribuir um conceito geral que camufla a essência das unidades menores. A operação do poema é uma presença que possui um poder de cognição. 0 avesso do poema é o outro lado do signo vazio de sentido. A leitura do poema revela a não possibilidade de abarcar um objeto absoluto, visto que o signo representa aquilo que ele não é. Desse modo, por ordenar-se num sistema de signos que representam apenas ideias e conceito geral, pode-se dizer que o poema imita a si mesmo. 0 sentido surge da transuasão, tornando o signo em poesia.

\section{REFERÊNCIAS}

ARAÚJO, Inês Lacerda. Do signo ao discurso: introdução à filosofia da linguagem. São Paulo: Parábola Editorial, 2004. (Língua(gem); 9)

BADIOU, Alain. Pequeno manual de inestética. Tradução Marina Appenzeller. São Paulo: Estação Liberdade, 2002.

CHANDLER, Daniel. Semiotics: the basics. $2^{\text {nd }}$ ed. New York: Taylor \& Francis eLibrary, 2007.

DEELY, John. Semiótica básica. Tradução Julio C. M. Pinto. São Paulo: Ática, 1990. (Série Fundamentos; 80)

DE WAAL, Cornelis. Sobre Pragmatismo. Tradução Cassiano Terra Rodrigues. São Paulo: Edições Loyola, 2007.

DURVAlino COUTO. Os caçadores de prosódias. Teresina: Projeto Petrônio Portela / Fundação Cultural do Piauí, 1994.

2 Estes tópicos foram analisados em outros capítulos da dissertação. 
KRESS, Gunther. Sociolinguistics and social semiotics. In: COBLEY, Paul (ed.). The Routledge companion to semiotics and linguistics. London and New York: Routledge /Taylor \& Francis e-Library, 2005, p. 66-82.

MERRELL, Floyd. Charles Sanders Peirce's concept of the sign. In: COBLEY, Paul (Ed.). The Routledge companion to semiotics and linguistics. London and New York: Taylor \& Francis e-Library, 2005, p. 28-39.

NASCIMENTO, Josivan Antonio do. Os caçadores de prosódias (1994): uma análise semiótica da poesia de Durvalino Couto. 2018, 229 f. : il. Dissertação (Mestrado em Letras) - Universidade Estadual do Piauí - UESPI, Mestrado Acadêmico em Letras, 2018.

PAZ, Octavio. Tradução: literatura e literalidade. Edição bilíngue; tradução Doralice Alves de Queiroz; apresentação Lucas Carvalho Soares de Aguiar Pereira. Belo Horizonte: FALE/UFMG, 2009.

PEIRCE, Charles Sanders. Semiótica. Tradução José Teixeira Coelho Neto; 4 ed. São Paulo: Perspectiva, 2010. (Estudos; 46; dirigida por J. Guinsburg)

Collected papers of Charles Sanders Peirce. Charles Hartshorne, Paul Weiss (vols. 1-6); Arthur W. Burks (vols. 7-8) (eds.). Cambridge: Harvard University Press, 1931-1958, 8 vols.

PIGNATARI, Décio. Semiótica \& Literatura. 6 ed. Cotia, SP: Ateliê Editorial, 2004.

SANTAELLA, Lúcia. O que é semiótica. São Paulo: Brasiliense, 2007. (Coleção primeiros passos; 103)

A assinatura das coisas: Peirce e a literatura. Rio de Janeiro: Imago, 1992.

SEBEOK, Thomas Albert. Signs: an introduction to semiotics. 2 ed. Toronto: University of Toronto Press, 2001. 